\title{
Abdominal myomectomy: A retrospective review of determinants and outcomes of complications at the University of Ilorin Teaching Hospital, Ilorin, Nigeria
}

\author{
1. Department of Obstetrics and Gynaecology, University of Ilorin, Ilorin, Nigeria \\ 2. Department of Obstetrics and Gynaecology, University of Ilorin Teaching Hospital, Ilorin, Nigeria
}

Kikelomo T. Adesina ${ }^{1,2}$, Beatrice O. Owolabi ${ }^{2}$, Hadijat O. Raji ${ }^{1,2}$, Adebunmi O. Olarinoye ${ }^{1,2}$

Correspondence: Dr Kikelomo T. Adesina (teminikike@yahoo.com)

\section{Background}

\section{Abstract}

The aim of this study was to describe the pattern, outcomes, and determinants of perioperative complications of abdominal myomectomy at the University of Ilorin Teaching Hospital, Ilorin, Nigeria.

Methods

This was a retrospective review of cases of abdominal myomectomy between January 2010 and December 2013. Data were obtained from ward and operating theatre case records and analysed using SPSS version 20. The continuous variables were analysed with Student's t-test. The categorical variables were analysed with the chi-square test. P-values of 0.05 or less was taken to be significant.

Results

Total sampling yielded 204 cases, of which 170 records (80\%) were adequate for analysis. Using criteria developed by Garry et al., major and minor complications occurred in $43.6 \%$ and $32.9 \%$ of procedures, respectively, while $23.5 \%$ of the patients had no complications. The commonest complication was intraoperative haemorrhage requiring blood transfusion. Mean estimated blood loss was $630.88 \pm 392.42 \mathrm{~mL}$. There were no cases converted to hysterectomy, and no deaths were recorded. Uterine size equivalent to 16 weeks' gestation or more was significantly associated with heavier blood loss, blood transfusion, and fever $(\mathrm{P}=0.034)$. Other significant determinants of major intraoperative haemorrhage with or without blood transfusion were menstrual flow of 6 days or more, preoperative anaemia, previous surgery, posterior incision, and surgery duration longer than 4 hours $(\mathrm{P}<0.05)$.

\section{Conclusions}

Outcome of abdominal myomectomy is generally favourable even if uterine size is greater than 16 weeks by palpation. Nevertheless, patients should be counselled preoperatively on the risk of blood loss and the possibility of blood transfusion.

\section{Introduction}

Uterine fibroids (leiomyomas) are the most common benign tumours of the uterus in women of childbearing age. ${ }^{1}$ They occur in $20 \%$ to $25 \%$ of women over the age of 30 years. $^{2}$ Abdominal myomectomy is the surgical removal of fibroid tissue through the abdominal route and is often performed for women who wish to retain their fertility or reproductive function. ${ }^{3}$ The incidence of abdominal myomectomy in southwestern Nigeria has been reported as $54.7 \%,{ }^{2}$ while a rate of $3.34 \%$ has been reported for Maiduguri, northeastern Nigeria. ${ }^{4}$ Abdominal myomectomy is the commonest method of treating uterine fibroids and accounts for $60.4 \%$ of cases in Ilorin ${ }^{5}$ and for $90 \%$ of cases in southeastern of Nigeria. ${ }^{6}$

Infertility secondary to uterine fibroid is one of the indications for myomectomy ${ }^{7}$; other indications include symptoms such as menorrhagia, recurrent pregnancy loss, dysmenorrhoea, lower abdominal swelling, and urinary frequency. ${ }^{8,9}$ Increasingly more women are requiring myomectomy as part of infertility management and, partially because of delayed childbearing, increasingly larger uterine myomas are seen in women who desire future fertility irrespective of their age or the number, size, and location of myomas. ${ }^{13}$ This increases the potential for complications, which can be intraoperative or postoperative. Intraoperative complications include intraoperative haemorrhage, injury to adjacent organs (such as bowel, ureter, and urinary bladder), and anaesthetic complications. ${ }^{10}$ Intraoperative blood loss is variable, depending on the size and location of the uterine fibroids. ${ }^{11}$ Unfortunately for women who undergo the procedure because of their desire to bear children, hysterectomy for uncontrollable haemorrhage is a known outcome of intended myomectomy. ${ }^{11}$ Postoperative complications include pyrexia, wound haematoma, and infection. ${ }^{10,12}$
Since myomectomy is a common surgical procedure in our setting, delineating the pattern and determinants of perioperative complications is important. Studies have shown that myomectomy is a safe alternative to hysterectomy for women who wish to preserve their reproductive function, with no significant difference in perioperative morbidity. ${ }^{14-16}$ It is therefore imperative to assess the safety of this uterus-conserving procedure and identify risk factors for surgical morbidity in order to ensure adequate preoperative preparation and reduce the overall morbidity associated with the procedure. The general complications of myomectomy have been enumerated by several authors ${ }^{1-8}$; the possibilities of predicting them in relation to presenting symptoms, signs, and ultrasonographic findings may guide gynaecologists in offering preoperative evaluation and counselling. Therefore, a retrospective review of documented findings was undertaken to possibly help guide gynaecologists in this respect. This study was designed to determine the pattern of perioperative complications of myomectomy and determinants of safety and outcomes at the University of Ilorin Teaching Hospital (UITH).

\section{Methods}

This was a descriptive, retrospective review of complications of abdominal myomectomy, carried out in the Department of Obstetrics and Gynaecology at UITH, Ilorin, Kwara State, Nigeria. The department runs 4 gynaecological clinics weekly under the supervision of consultant staff. Cases for surgery are admitted into the gynaecological ward for preoperative and anaesthetic reviews a few days before scheduled operation days. Operations are carried out in the gynaecological suites in the main operating theatre and transferred thereafter to the gynaecological ward for postoperative care. Patients are booked for clinic follow-up 
2 weeks after surgery and then monthly for 3 months. If there are complications or complaints, consultant review may be warranted outside of these scheduled appointments. Patient follow-up for the case notes reviewed in this study was limited to 4 weeks.

Case notes of gynaecological patients who had abdominal myomectomy at UITH between January 2010 and December 2013 were reviewed retrospectively. The information was obtained from case folders, anaesthetist operation charts, and gynaecological ward and operating theatre records. Other gynaecological operations during the period under review were excluded.

The sociodemographic characteristics of the patients, comorbidities, previous surgeries and past obstetric history, indications for myomectomy, uterine size, and fibroid locations were retrieved from case folders.

Preoperative assessments and investigations were noted, and pertinent intraoperative data included estimated blood loss during surgery, as well as information on anaesthetic complications, injury to adjacent organs (such as bowel, ureter, or urinary bladder), and duration of surgery. Study staff also recorded if conversion to hysterectomy (because of uncontrolled haemorrhage) occurred, and if (and how much) blood was required for transfusion, among other findings. Postoperative complications were also noted, including any postoperative haemorrhage, anaemia, fever (temperature $\geq 38^{\circ} \mathrm{C}$, occurring within 24 hours of surgery), wound infection, wound haematoma, duration of hospital stay, postoperative pain, reoperation within 5 days of surgery, and readmission after discharge from the hospital within 14 days. The complications were divided into minor and major according to the criteria described by Garry et al. ${ }^{17}$ Preoperative and postoperative PCV and the differences between these figures were also recorded for each patient included in the study.

Blood loss estimates from the operative notes reviewed for this study were calculated by summing estimates of blood collected intraoperatively via suction, abdominal packs, and absorbent gauze. A fully soaked standard abdominal pack is estimated to absorb $150 \mathrm{~mL}$ of blood, while the standard gauze sheets used at UITH are estimated to absorb $15 \mathrm{~mL}$. For procedures carried out in the department, the allowable blood loss (ABL) for each patient is calculated using the formula:

$$
\mathrm{ABL}=\frac{\text { Total blood volume } \times(\text { expected PCV }- \text { threshold PCV })}{\text { preoperative PCV }}
$$

Patients are transfused intraoperatively when this limit is reached. Transfusion may also be commenced if there is undesirable blood loss with features of hypovolaemic shock. Postoperatively, blood is transfused if there is symptomatic anaemia or hypovolaemic shock.

This was a retrospective review and post hoc analysis of statistical power using the observed proportion of complications in the study, compared to a past report of $10.9 \%,{ }^{4}$ determined a power greater than $80 \%$, as calculated using the following formula for post hoc analysis of a retrospective study ${ }^{18}$ :

$$
\mathrm{N}=\frac{\mathrm{p}_{0} \mathrm{q}_{0}\left(\mathrm{z}_{1-\alpha / 2}+\mathrm{z}_{1-\beta} \sqrt{\left.\mathrm{p}_{1} \mathrm{q}_{1} / \mathrm{p}_{0} \mathrm{q}_{0}\right)^{2}}\right.}{\left(\mathrm{p}_{1}-\mathrm{p}_{0}\right)^{2}}
$$

Where,

$\mathrm{N}=$ minimum number of subjects that need to be enrolled in the study to have a statistical power of $80 \%$

$\mathrm{p}_{0}=$ proportion of sample with postoperative complications from a similar study, ${ }^{4} 10.9 \%$

$\mathrm{p}_{1}=$ proportion of sample with postoperative complications from this study group, $76.5 \%$

$\mathrm{q}_{0}=1-\mathrm{p}_{0}$

$\mathrm{q}_{1}=1-\mathrm{p}_{1}$

$\alpha=$ probability of type I error, 0.05

$\beta=$ probability of type II error, 0.02

$z=$ critical value for a given $\alpha$ or $\beta$.

Setting power at $80 \%$ (the minimum power), $\mathrm{N}=128$.

This study used 170 patient records, exceeding the the minimum number required for $80 \%$ power.

Data were analysed using SPSS software, version 20 (IBM). The relationships between complications, clinical presentations, packed cell volumes, and intraoperative events and findings were determined using Student's t-test (for continuous variables) and the chi-square test (for catergorical variables). P-values of 0.05 or less were taken to be significant.

Institutional ethical approval was obtained from the UITH Ethical Research Committee before the commencement of the study. Confidentiality of patient information was maintained throught the conduct of this study.

\section{Results}

Total enumeration of all records of abdominal myomectomy during the period yielded 204 cases; 170 records were adequate for analysis, giving a retrieval rate of $80 \%$. The sociodemographic characteristics of the patients are shown in Table 1. The mean age of the population was $34.3 \pm 5.6$ years. The majority $(70.1 \%)$ had tertiary education and $77.1 \%$ were nulliparous. The case records included in the analysis were those of myomectomies performed by 12 different consultant gynaecologists.

Figure 1 shows the clinical presentations of the patients. Most patients had at least 2 presenting complaintsthe commonest was abdominal swelling, followed by menorrhagia and infertility. On examination, uterine size was greater than the equivalent of 16 weeks' gestation in about half $(52.9 \%)$ of the patients; $35.9 \%$ had 12 - to 16 -week-sized uteruses; others were less than 12 weeks.

Frequencies of major and minor complications ${ }^{17}$ during and after surgery are shown in Table 2 . There were complications in $76.5 \%$ of all patients who underwent myomectomy; $43.6 \%$ of all procedures brought about major complications, while $32.9 \%$ produced minor complications. The commonest complication was primary haemorrhage in $45.3 \%$ of procedures; mean blood loss was $630.9 \pm 392.4 \mathrm{~mL}$. The estimated blood loss was less than $500 \mathrm{~mL}$ in $28.8 \%$ of cases; $44.1 \%$ had blood loss between $500 \mathrm{~mL}$ and $1000 \mathrm{~mL}$, while blood loss was greater than $1000 \mathrm{~mL}$ in $27.1 \%$ of all myomectomies. Ninety-nine patients $(58.2 \%)$ required blood transfusion; 3.5\% received at least 5 units of blood, $42.9 \%$ received 2 to 4 units, while 20 patients $(20.2 \%)$ received 1 unit. Only 1 patient had an anaesthetic complication (anaesthesia-related hypotension). The fallopian tubes were the most commonly injured organs.

Duration of admission ranged between 7 and 14 days. Two patients were readmitted within 14 days of discharge: 1 on 
Table 1: Sociodemographic characteristics

$\begin{array}{cc}\text { Variable } & \text { Frequency } \\ (\mathbf{N}=170) & \text { Percent }\end{array}$

\section{Age group (years)}

$\begin{array}{ccc}\leq 25 & 4 & 2.4 \\ 26-30 & 52 & 30.6 \\ 31-35 & 52 & 30.6 \\ 36-40 & 41 & 24.1 \\ 41-45 & 16 & 9.4 \\ \geq 46 & 5 & 2.9 \\ \text { Mean } \pm \text { SD } & 34.3 \pm 5.6 \text { years }\end{array}$

\section{Marital status}

Single

Married

Divorced

Separated

\section{Educational status}

Primary

Secondary

Tertiary

Others

Ethnicity

Yoruba

Hausa

Igbo

Others

Parity

$\begin{array}{lcc}\text { Nulliparous } & 131 & 77.0 \\ \text { Primiparous } & 19 & 11.2 \\ \text { Multiparous } & 19 & 11.2 \\ \text { Grand-multiparous } & 1 & 0.6\end{array}$

account of abdominal pain and vaginal bleeding, while the other was on account of postoperative pyrexia. In this series, no cases were converted to hysterectomy and no deaths occurred.

\section{Correlates and determinants of complications of myomectomy}

The duration of menstrual flow was significantly associated with requirement for blood transfusion during and after myomectomy ( $\mathrm{P}<0.001)$; 99 patients were transfused and $20(20.2 \%)$ of them had menstrual flow of 6 days or more. The presence of abdominal swelling with an estimated size of 16 weeks' gestation or more was also significantly related
Table 1: Sociodemographic characteristics (continued)

\begin{tabular}{lc}
\hline Variable & Frequency \\
& $(\mathrm{N}=170)$ \\
\hline
\end{tabular}

\section{Occupation}

$\begin{array}{lcc}\text { Trader } & 57 & 33.5 \\ \text { Civil servant } & 35 & 20.6 \\ \text { Student } & 28 & 16.5 \\ \text { Artisan } & 15 & 8.8 \\ \text { Teacher } & 13 & 7.6 \\ \text { Professional } & 11 & 6.5 \\ \text { Unemployed } & 5 & 2.9 \\ \text { Others } & 6 & 3.6\end{array}$

\section{Partner's}

\section{occupation}

Artisan

Civil servant $\quad 40$

Others

Professional

Trader

22

\section{Husband's}

\section{educational status}

Primary

5

Secondary

Tertiary

65

38.2

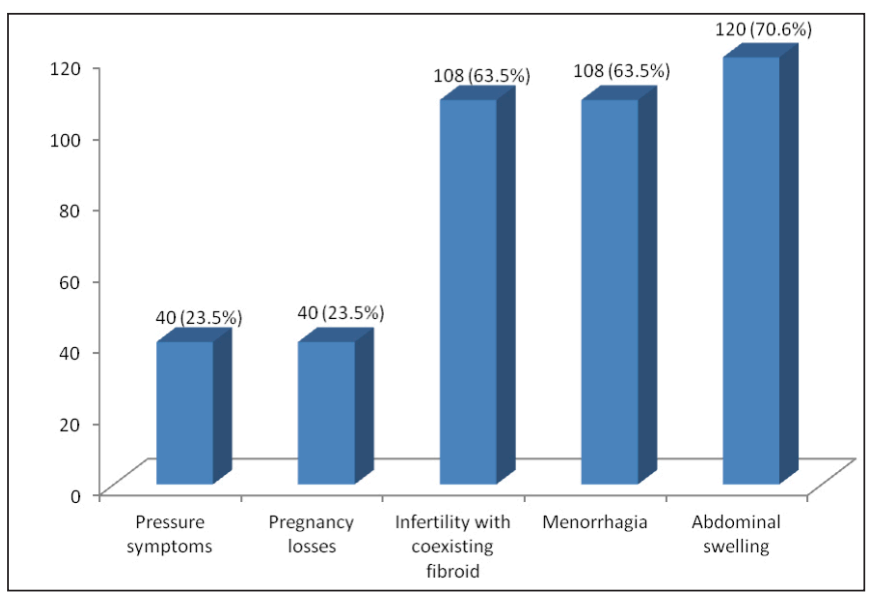

Figure 1: Presenting complaints of patients who underwent myomectomy

Note: some patients had multiple complaints to the occurrence of myomectomy-related complications $(\mathrm{P}=0.013$, odds ratio $[\mathrm{OR}]=3.83,95 \%$ confidence interval $[\mathrm{CI}]=1.15$ to 13.45$)$. There was no statistically significant association between the presence of either dysmenorrhoea or infertility and myomectomy complications ( $\mathrm{P}>0.05)$.

Table 3 shows that a uterine size greater than 16 weeks was significantly associated with blood loss of $500 \mathrm{~mL}$ or more 
Table 2: Major and minor complications after myomectomy using Garry's criteria ${ }^{17}$

\begin{tabular}{lcc}
\hline Complications & $\begin{array}{c}\text { Frequency } \\
(\mathbf{N}=\mathbf{1 7 0})\end{array}$ & Percent \\
\hline Major complications & 36 & 21.2 \\
Major intraoperative bleeding requiring blood transfusion & 12 & 7.1 \\
Post operative bleeding requiring blood transfusion & 1 & 0.6 \\
Pelvic or wound haematoma requiring drainage or blood transfusion & 16 & 9.4 \\
Injury to bladder, bowel, ureter, adnexae & 0 & 0.0 \\
Conversion to hysterectomy & 0 & 0.0 \\
Pulmonary embolism & 1 & 0.6 \\
Return to theatre within 3 to 5 days & 3 & 1.8 \\
Wound dehiscence & 5 & 2.9 \\
Readmission within 14 days of surgery & & \\
Minor complications & 41 & 24.1 \\
Haemorrhage $<500$ mL not requiring blood transfusion & 3 & 1.8 \\
Haematoma not requiring drainage & 0 & 0.0 \\
Deep venous thromboembolism & 5 & 2.9 \\
Wound infection & 7 & 4.1 \\
Fever $\geq 38^{\circ} \mathrm{C}$ & &
\end{tabular}

Table 3: Comparison of uterine size and perioperative complications

\begin{tabular}{|c|c|c|c|c|c|c|}
\hline \multirow{2}{*}{ Variable } & \multicolumn{4}{|c|}{$\begin{array}{l}\text { Size of uterus (gestational week equivalent) } \\
\qquad(\mathrm{N}=170)\end{array}$} & \multirow[b]{2}{*}{$\mathrm{X}^{2}$} & \multirow[b]{2}{*}{ P value } \\
\hline & $\begin{array}{l}<12 \\
\text { n }(\%)\end{array}$ & $\begin{array}{l}12 \text { to } 14 \\
\text { n }(\%)\end{array}$ & $\begin{array}{l}15 \text { to } 16 \\
\text { n }(\%)\end{array}$ & $\begin{array}{l}>16 \\
\text { n }(\%)\end{array}$ & & \\
\hline \multicolumn{7}{|l|}{ Estimated blood loss } \\
\hline$<500 \mathrm{~mL}$ & $10(52.6)$ & $15(45.5)$ & $7(25.0)$ & $17(18.9)$ & 21.92 & $<0.001^{*}$ \\
\hline $500 \mathrm{~mL}$ to $1000 \mathrm{~mL}$ & $5(26.3)$ & $10(30.3)$ & $10(35.7)$ & $50(55.6)$ & 13.71 & $<0.003^{*}$ \\
\hline$>1000 \mathrm{~mL}$ & $4(21.1)$ & $8(24.2)$ & $11(39.3)$ & $23(25.6)$ & 7.07 & 0.069 \\
\hline \multicolumn{7}{|l|}{$\begin{array}{l}\text { Major intraoperative } \\
\text { bleed }\end{array}$} \\
\hline Yes & $3(15.8)$ & $3(9.1)$ & $5(17.9)$ & $25(27.8)$ & 10.18 & $0.017^{*}$ \\
\hline No & $16(84.2)$ & $30(90.9)$ & $23(82.1)$ & $65(72.2)$ & 2.18 & 0.535 \\
\hline \multicolumn{7}{|l|}{$\begin{array}{l}\text { Haemorrhage } \\
<500 \mathrm{~mL}\end{array}$} \\
\hline Yes & $2(10.5)$ & $7(21.2)$ & $4(14.3)$ & $28(31.1)$ & 12.73 & $0.005^{*}$ \\
\hline No & $17(89.5)$ & $26(78.8)$ & $24(85.7)$ & $62(68.9)$ & 3.04 & 0.385 \\
\hline \multicolumn{7}{|l|}{$\begin{array}{l}\text { Requirement for } \\
\text { blood transfusion }\end{array}$} \\
\hline Yes & $6(31.6)$ & $13(39.4)$ & $21(75.0)$ & $59(65.6)$ & 24.30 & $<0.001^{*}$ \\
\hline No & $13(68.4)$ & $20(60.6)$ & $7(25.0)$ & $31(34.4)$ & 27.30 & $<0.001^{*}$ \\
\hline \multicolumn{7}{|l|}{ Fever } \\
\hline Yes & $0(0.0)$ & $1(3.07)$ & $3(10.7)$ & $3(3.3)$ & 6.71 & $0.034^{*}$ \\
\hline No & $19(100.0)$ & $32(97.0)$ & $25(89.3)$ & 87 (96.7) & 0.65 & $<0.885$ \\
\hline
\end{tabular}

$(\mathrm{P}<0.003)$ and major intraoperative blood loss necessitating transfusion $(\mathrm{P}=0.017)$. Febrile morbidity was higher as uterine size increased, and this was statistically significant $(\mathrm{P}$ $=0.034$ ).

Complications were analysed according to preoperative PCV, as shown in Table 4. Among the 143 patients who had a PCV of $30 \%$ or more before surgery, $19.6 \%$ had a blood loss of $500 \mathrm{~mL}$ or more; the majority of patients had less blood loss than this.

Haemostatic techniques used were tourniquet at the uterine isthmus (94.7\%), intramyometrial vasopressin (1.8\%), and both $(3.5 \%)$. In terms of blood loss, none of the haemostatic techniques provided significantly better outcomes than the others. No comparison was done between use and nonuse of haemostatic methods, because at least 1 haemostatic technique was used in all procedures included in this series.

Anterior and posterior incisions were used in 55.9\% and
Table 4: Relationship between preoperative packed cell volume (PCV) and complications

\begin{tabular}{|c|c|c|c|c|}
\hline \multirow[b]{2}{*}{ Variable } & \multicolumn{2}{|c|}{ Preoperative PCV $(\mathrm{N}=170)$} & \multirow[b]{2}{*}{$\mathrm{X}^{2}$} & \multirow[b]{2}{*}{ P-value } \\
\hline & $\begin{array}{l}<30 \% \\
\text { n (\%) }\end{array}$ & $\begin{array}{l}\geq 30 \% \\
\text { n (\%) }\end{array}$ & & \\
\hline \multicolumn{5}{|l|}{ Estimated blood loss } \\
\hline$<500 \mathrm{~mL}$ & $5(18.5)$ & $44(30.8)$ & 3.069 & 0.079 \\
\hline $500 \mathrm{~mL}$ to $1000 \mathrm{~mL}$ & $15(55.6)$ & $69(42.0)$ & 1.895 & 0.168 \\
\hline$>1000 \mathrm{~mL}$ & $7(25.9)$ & $39(27.3)$ & 0.037 & 0.847 \\
\hline \multicolumn{5}{|l|}{ Major intraoperative bleed } \\
\hline Yes & $4(14.8)$ & $32(22.4)$ & 1.553 & 0.212 \\
\hline No & $23(85.2)$ & $111(77.6)$ & 0.355 & 0.551 \\
\hline \multicolumn{5}{|l|}{ Haemorrhage $<500 \mathrm{~mL}$} \\
\hline Yes & $13(48.1)$ & $28(19.6)$ & 11.998 & $<0.001^{*}$ \\
\hline No & $14(51.9)$ & $115(80.4)$ & 6.139 & $0.013^{*}$ \\
\hline \multicolumn{5}{|l|}{ Wound infection } \\
\hline Yes & $0(0.0)$ & $5(3.5)$ & $0.071^{\mathrm{Y}}$ & $<0.001$ \\
\hline No & $27(100.0)$ & $138(96.5)$ & 0.062 & $<0.803$ \\
\hline \multicolumn{5}{|l|}{ Fever } \\
\hline Yes & $1(3.7)$ & $6(4.2)$ & $0.032^{\mathrm{Y}}$ & 0.858 \\
\hline No & $26(96.3)$ & $137(95.8)$ & 0.001 & 0.974 \\
\hline
\end{tabular}

$\mathrm{X}^{2}=$ chi-square statistic; ${ }^{\mathrm{Y}}=$ Yates corrected chi-square; ${ }^{*}=$ statistically significant

Table 5: Relationship between uterine incision location and estimated blood loss

\begin{tabular}{|c|c|c|c|c|c|}
\hline \multirow[b]{2}{*}{ Variable } & \multicolumn{3}{|c|}{ Estimated blood loss $(\mathrm{mL})$} & \multirow[b]{2}{*}{$X^{2}$} & \multirow[b]{2}{*}{ P-value } \\
\hline & $\begin{array}{l}<500 \\
\text { n (\%) }\end{array}$ & $\begin{array}{c}500 \text { to } 1000 \\
\text { n (\%) }\end{array}$ & $\begin{array}{l}>1000 \\
\text { n (\%) }\end{array}$ & & \\
\hline \multicolumn{6}{|l|}{ Uterine incision } \\
\hline Anterior & $29(59.2)$ & $36(48.0)$ & $30(65.2)$ & 2.65 & 0.27 \\
\hline Posterior & $4(8.2)$ & $16(21.3)$ & $6(13.0)$ & 6.20 & $0.045^{*}$ \\
\hline Anteroposterior & $16(32.7)$ & $23(30.7)$ & $10(21.7)$ & 2.42 & 0.30 \\
\hline & \multicolumn{3}{|c|}{ Uterine incision site } & & \\
\hline & $\begin{array}{c}\text { Anterior } \\
\text { n (\%) }\end{array}$ & $\begin{array}{c}\text { Posterior } \\
\text { n (\%) }\end{array}$ & $\begin{array}{c}\text { Antero- } \\
\text { posterior } \\
\text { n (\%) }\end{array}$ & & \\
\hline \multicolumn{6}{|l|}{ Estimated blood loss } \\
\hline$<500 \mathrm{~mL}$ & $29(30.5)$ & $4(15.4)$ & $16(32.7)$ & 6.77 & $0.033^{*}$ \\
\hline $500 \mathrm{~mL}$ to $1000 \mathrm{~mL}$ & $36(37.9)$ & $16(61.5)$ & $23(46.9)$ & 5.82 & 0.054 \\
\hline$>1000 \mathrm{~mL}$ & $30(31.6)$ & $6(23.1)$ & $10(20.4)$ & 2.73 & 0.26 \\
\hline
\end{tabular}

$\mathrm{X}^{2}=$ chi-square statistic; ${ }^{*}=$ statistically significant

$15.3 \%$ of procedures, respectively, while anteroposterior incisions were employed in $28.8 \%$ of cases. The use of posterior uterine incision was significantly associated with increased blood loss $(\mathrm{P}=0.045)$, while anterior incisions had the least blood loss (see Table 5).

Using multivariate analysis, a uterine size of greater than 16 weeks was a significant predictor of major intraoperative bleeding $(\mathrm{P}=0.033, \mathrm{OR}=4.14,95 \% \mathrm{CI}=1.12$ to 15.27$)$. Uterine size $(\mathrm{P}=0.035, \mathrm{OR}=3.68 .95 \% \mathrm{CI}=1.10$ to 12.36$)$ and previous gynaecological surgery $(\mathrm{P}=0.008, \mathrm{OR}=8.049$, $95 \%$ CI $=1.72$ to 37.66$)$ were also statistically significant predictors of blood transfusion post-myomectomy. The previous surgeries documented were myomectomies and exploratory laparotomies for ectopic gestations and ovarian cysts. There was also a significant association between intraoperative haemorrhage (greater than $500 \mathrm{~mL}$ of blood loss) and duration of surgery (longer than 4 hours) $(\mathrm{P}=0.004, \mathrm{OR}=1.95,95 \% \mathrm{CI}=1.31$ to 2.93$)$. Using a 
binary logistic regression model, uterine size was found to best predict blood loss of $500 \mathrm{~mL}$ or more, after excluding number and location of fibroids $(\mathrm{B}=0.66, \mathrm{P}=0.003, \mathrm{OR}=$ $1.93,95 \% \mathrm{CI}=1.25$ to 2.97$)$.

\section{Discussion}

The mean age of patients included in this study was $34.3 \pm$ 5.6 years. They were all Nigerians of different ethnicities. This is comparable to an American study where the incidence of uterine fibroids was $60 \%$ at 35 years among AfricanAmerican women. ${ }^{19}$ Fibroids are commoner among women of African descent than among Caucasians and Asians. This suggests a probable role of genetics in the aetiopathogenesis of uterine leiomyomas.

There is evidence of an inverse relationship between the incidence of fibroids and parity. Pregnancy is known to be protective against fibroids; ischaemia of the uterus during parturition and selective apoptosis of small lesions during postpartum uterine remodelling are possible explanations. ${ }^{20-22}$ In this study, the commonest presenting complaint and indication for myomectomy was abdominal swelling, followed by menorrhagia and infertility. This is comparable with findings from Maiduguri, Nigeria ${ }^{4}$ but differs from results of other studies in which menorrhagia was found to be the commonest presenting complaint., 44,21,22 The difference may be that this review had a more selective study sample, while others were epidemiologic descriptive studies of larger sample size. All the same, the presence of a large fibroid seems to be a more common reason to require surgery in our environment.

Fibroids caused uterine sizes of greater than 16 weeks' gestation in half of the clients included in this study, and this was a major predictor of intraoperative haemorrhage and blood transfusion. Ngichabe et al., in a randomised trial similarly reported on the correlation between myoma volume and blood loss at open myomectomy. ${ }^{23}$ In our series, $74.8 \%$ of the patients had complications at myomectomy, based on Garry's criteria. ${ }^{17}$ Primary intraoperative haemorrhage was the leading complication and $58.2 \%$ of the patients required blood transfusion. Pundir et al., in an analysis of 200 abdominal myomectomies, found that uterine size of 20 weeks or more was a major predictor of perioperative bleeding requiring blood transfusion. ${ }^{24}$ Similarly, West and his colleagues reported that 77 out of the 91 cases of abdominal myomectomy required blood transfusion for perioperative blood loss. ${ }^{25}$ One feature common to these reports and our study is the operation of large uterine fibroids, defined as uterine size of 16 weeks or more. It is imperative to counsel patients on the possibility of blood transfusion whenever myomectomy is performed.

In terms of blood loss, there was no significant differences between the intraoperative haemostatic techniques (tourniquet and myometrial injection of vasopressin) used in the procedures analysed. The most practiced haemostatic method during myomectomy in our centre was the tying of tourniquet around the cervico-isthmic junction of the uterus. This is usually done for 30 to 45 minutes to prevent unwanted ischaemic injury and release of toxic metabolites. Vasopressin was used alone for 3 patients and in combination with tourniquet in another 6 patients. There was no patient for whom at least 1 haemostatic technique was not used. Prospective studies on the role of haemostatic techniques in abdominal myomectomies are needed. Use of preoperative medical agents, such as gonadotropin-releasing hormone (GnRH) agonists, to reduce fibroid size, help reduce the incidence of intraoperative haemorrhage, but none of the patients studied received such interventions. Other agents that cause shrinkage in fibroid size include mifepristone, aromatase inhibitors, and ulipristal ${ }^{26-28}$; these medications are not without side effects.

These results show that, even though myomectomy is feasible and relatively safe, with large fibroids there is increased risk of heavy blood loss and blood transfusion. This may have contributed to the substantial febrile morbidity observed in this study, as fever is a common blood transfusion reaction. Another cause of post-myomectomy pyrexia is haematoma formation; it may follow improper obliteration of cavities after enucleation of fibroids. Earlier reports also highlighted the risk of febrile morbidity after myomectomy, as demonstrated in this study. ${ }^{16,24,25}$

Of the patients who lost less than $500 \mathrm{~mL}$ of blood, $80.4 \%$ of them had a preoperative PCV of at least 30\% ( $\mathrm{P}=$ 0.013). Adequate PCV may suggest better oxygenation of myometrial cells and therefore appropriate circulatory and metabolic responses to surgical trauma. It may also be that a high concentration of red cells may indirectly reflect a high concentration of other blood cells, including leucocytes and platelets. Although this study did not review the role of white cell count and platelet count in myomectomy outcomes, platelets, of course, contribute to the efficiency of blood coagulation and help reduce excessive blood loss. Effects of other haematological parameters on intraoperative blood loss during myomectomy could not be determined in this study. This limitation highlights the need for future research into the roles of blood parameters in evaluating myomectomy outcomes. Other contributing factors to haemorrhage in this study were use of posterior uterine incision and previous gynaecological surgeries.

Duration of surgery longer than 4 hours was significantly related to occurrence of complications $(\mathrm{P}=0.004)$. This was contrary to a report by Geidam et al., from Maiduguri, ${ }^{4}$ where duration of surgery was not a significant factor in the development of complications. This is probably because the authors also reported that most of the procedures in the Maiduguri study lasted between 60 and 120 minutes. Other investigators have demonstrated an independent correlation between increased operative time and increased perioperative morbidity during abdominal myomectomy; the likelihood of blood transfusion, pulmonary embolism, and other complications is increased by increased operative time. ${ }^{29}$ These were more common among patients with operation time greater than 3 hours. Presence of multiple fibroids, size of fibroids, and the need to secure haemostasis are common reasons for prolonged operation time during abdominal myomectomy.

For counselling, uterine size less than 16 weeks is associated with fewer complications, as is a preoperative PCV of $30 \%$ or more. Avoidance of posterior incisions and use of a tourniquet are recommended..$^{30}$

This was a retrospective review of 170 cases of abdominal myomectomy. Patient follow-up was limited to 2 to 4 weeks after surgery, making it difficult to determine outcome after this duration.

The myomectomies included in this study were performed by various surgeons with differing expertise and experience levels. Such variations affect duration of surgery and other 
intraoperative events. With that said, a retrospective review of this kind is likely to remove assumptions and biases that can occur in prospective designs. However, it is important to consider prospective randomised designs with explicit criteria, so as to eliminate confounders; for example, this review did not distinguish between abdominal myomectomies performed as either emergencies or elective cases.

Estimation of blood loss during surgery is a better assessment of haemorrhage than difference in PCV before and after operation. As per departmental protocol, surgeons employed tourniquet application as a haemostatic method, while vasopressin was added infrequently to further reduce haemorrhage, which affected the true blood loss at surgery. In addition, regional anaesthetic techniques, such as subarachnoid block, are associated with hypotensive effects that impact significantly on blood loss at surgery. Variations in anaesthetic technique, as well as the experience and expertise of the surgeons in this study, should be considered when interpreting the results of this study.

\section{Conclusions}

Intraoperative haemorrhage necessitating blood transfusion is the most common and significant complication that can follow abdominal myomectomy. Uterine size, anaemia, prolonged surgery time, and posterior uterine incision are significant determinants of complications. Determinants of reduced blood loss and decreased likelihood of blood transfusion include uterine size less than 16 weeks' gestation, absence of preoperative anaemia, and avoidance of posterior uterine incision where possible.

\section{Competing interests}

The authors declare that they have no conflicts of interest.

\section{References}

1. Omole - Ohonsi A, Belga F. Surgical management of uterine fibroids at Aminu Kano Teaching Hospital. Obstet Gynecol Intl. 2012; 702325: 1 - 6.

2. Okogbo FO, Ezechi OC, Loto OM, Ezeobi PM. Uterine Leiomyomata in Southwestern Nigeria: A clinical study of presentations and management outcome. Afri Health Sci. 2011; 11(2): 271 - 278.

3. Okeke TC, Okezie, OA, Obioha KC, Ikeako LC, Enzeaku CC. Trends of Myomectomy at the University of Nigeria Teaching Hospital Enugu Nigeria. Niger J Med. 2011; 20(2): 224 - 227.

4. Geidam AD, Lawan ZM, Chama C, Bako BG. Indications and outcome of abdominal myomectomy in University of Maiduguri Teaching Hospital: Review of ten year. Nigeria Med J. 2011; 52(3):158-162.

5. Omokanye LO, Salaudeen GA, Saidu R,et al. Surgical management of uterine fibroid at the University of Ilorin Teaching Hospital: A 5 year Review. Global Research J of Med. 2012; 2(2): 018-022.

6. Obuna JA, Umeora OUJ, Ejikeme BN, et al. Uterine fibroids in a tertiary Health Centre South East Nigeria. Nig J. of Med. 2008; 17 (4): 447 - 451

7. Obed JY, Babo B, Kadas S, et al. The benefit of myomectomy in women aged 40years and above: Experience in Urban Teaching Hospital in Nigeria. Niger Med J. 2011; 52 (3): 158 - 162.

8. Ikeako CL, Hezegwu IU, Okeke T,et al. myomectomy in a Secondary Health Centre in Awka, South East Nigeria. Orient J Med. 2012; 24 (3): $1-6$.

9. Kemfang NJD, Kasia JM, Nke ZH, Neng HT. High incidence of adn xal adhesions formation after abdominal myomectomy among African women. J of Pharmaceutical and Biomedical Sci. 2012; 18 (06): 1 - 4.
10. Kunde K, Cortes E, Seed P, Khalat Y. Eradication of Perioperative morbidity associated with single and multiple myomectomy. J of obstet gynecol. 2009; 29(8): 737 - 741.

11. Marquad KL, Rivlin ME, helmow D. Gynecolgoic Myomectomy: Treatment and Management. Medscape 2011; article 267 - 677.

12. Iftikhar R. Outcome of abdominal myomectomy. J of Surgery Pakistan. 2009; 14 (2): 85 - 88.

13. Talaulikar VS, Gupta S, Mayonda I. Pregnancy after complex myomectomy: neither age of patient nor size, number or location of fibroids should be a barrier. JSRM Short Rep 2012;3(3):19-34.

14. Mohammed MB, NoorAli R, Anandakumar C. Uterine fibroid : clinical presentations and relative morbidities of abdominal myomectomy and total abdominal hysterectomy in a teaching hospital of Karachi, Pakistan. Singapore medical journal 2002; 43(6):289-295

15. PundirJ, Walawalkar R, Seshadri S, Khalaf Y,El-Toukhy T. Perioperative morbidity associated with abdominal myomectomy compared with total abdominal hysterectomy for uterine fibroids. J Obstet Gynaecol 2013; 33(7): 655-662.

16. Sawin SW, Pilevsky ND, Berlin JA, Barnhart KT. Comparability of perioperative morbidity between abdominal myomectomy and hysterectomy for women with uterine leiomyomas. Am J Obstet Gynecol 2000;183 (6); 1448-1455

17. Garry R, Fountain J, Mason S, et al. The evaluate study: two parallel randomised trials, one comparing laparoscopic with abdominal hysterectomy, the other comparing laparoscopic with vaginal hysterectomy. BMJ. 2004; 328(7432): 129.

18. Rosner B. Fundamentals of Biostatistics. 7th ed. Boston, MA: Brooks/ Cole; 2011.

19. Day Baird D, Dunson DB, Hill MC, Cousins D, Schectman JM. High cumulative incidence of uterine leiomyoma in black and white women: ultrasound evidence. Am J Obstet Gynecol. 2003;188(1):100-107.

20. Baird DD, Dunson DB. Why is parity protective for uterine fibroids? Epidemiology.2003;14(2):247-250

21. Parazzini F. Risk factors for clinically diagnosed uterine fibroids in women around menopause. Maturitas. 2006;55(2):174-179.

22. Wise LA, Palmer JR, Harlow BL, et al. Reproductive factors, hormonal contraception, and risk of uterine leiomyomata in African-American women:a prospective study. Am J Epidemiol. 2004;159(2):113-123.

23. Ngichabe S, Obura T, Stones W. Intravenous tranexamic acid as an adjunct haemostat to Ornipressin during open myomectomy. A randomized double blind placebo controlled trial. Ann Surg Innov Res.2015; 9: 10 DOI 10.1186/s13022-015-0017-y

24. Pundir J, Krishnan N, Siozos A, et al. Perioperative morbidity associated with abdominal myomectomy for very large uterine fibroids. Eur J Obstet Gynecol Reprod Biol.2013;167(2):219-24.

25. West S, Ruiz R, Parker WH. Abdominal Myomectomy in women with very large uterine size. Fertility and Sterility. 2006; 85:36-39.

26. Carbonell Esteve JL, Acosta R, Heredia B, Pérez Y, Castañeda MC, Hernández AV. Mifepristone for the treatment of uterine leiomyomas: a randomized controlled trial. Obstet Gynecol. 2008;112:1029-1036.

27. Varelas FK, Papanicolaou AN, Vavatsi-Christaki N, Makedos GA, Vlassis GD. The effect of anastrazole on symptomatic uterine leiomyomata. Obstet Gynecol. 2007;110(3):643-649.

28. Donnez J, Tatarchuk TF, Bouchard P, et al. PEARL I Study Group Ulipristal acetate versus placebo for fibroid treatment before surgery. $\mathrm{N}$ Engl J Med. 2012;366:409-42.

29. Catanzarite T, Saha S, Rambachan A, Kim JY, Milad M. Impact of operative time on perioperative morbidity in abdominal myomectomy. JMIG. 2014 ;21: 34-35

30. Ikechebelu JI, Ezeama CO, Obiechina NJA. The use of tourniquet to reduce blood loss at myomectomy . Nig. J Clin Pract.2010;13(2):154-158. 